\title{
A Study in Engaging Female Students in Computer Science Using Role Models
}

\author{
Jonathan Black \\ Queen Mary University of \\ London \\ Mile End Road, \\ London. E1 4NS \\ +442078827559 \\ jonathanb@ \\ eecs.qmul.ac.uk
}

\author{
Paul Curzon \\ Queen Mary University of \\ London \\ Mile End Road, \\ London. E1 4NS \\ +442078825212 \\ pc@eecs.qmul.ac.uk
}

\author{
Chrystie Myketiak \\ Queen Mary University of \\ London \\ Mile End Road, \\ London. E1 4NS \\ +442078827559 \\ chrystie@ \\ eecs.qmul.ac.uk
}

\author{
Peter W. McOwan \\ Queen Mary University of \\ London \\ Mile End Road, \\ London. E1 4NS \\ +442078825224 \\ pmco@ \\ eecs.qmul.ac.uk
}

\begin{abstract}
An effective approach to engaging young women to take computing in higher education is to provide examples of successful female computer scientists. Can a print publication that combines core computing concepts with inspiring stories of women in the field be effective? In this paper, we describe a campaign that distributed a 60-page booklet on women in computing to UK secondary schools. We analyse the initial response from teachers, and draw some general conclusions from the project. Teachers expressed strong enthusiasm for the booklet, and also report the desire for recruitment and retention of girls in their computing programmes. They had confidence in the potential for this booklet to inspire young women to take computing.
\end{abstract}

\section{Categories and Subject Descriptors}

K.3.2 [Computers and Education]: Computer and Information Science Education - Computer Science Education

\section{General Terms}

Human Factors.

\section{Keywords}

Public engagement, outreach, recruitment, gender issues, K-12, teachers, girls, representation, diversity, cs4fn.

\section{INTRODUCTION}

The often forgotten story of women in computing is rich and diverse, and reaches back to the very beginning of the field itself. It is also, unfortunately, a story in which women have mostly been a minority within the field. In recent years more attention has been drawn to the imbalance between the genders in computing, and many excellent initiatives are attempting to change this imbalance

Permission to make digital or hard copies of all or part of this work for personal or classroom use is granted without fee provided that copies are not made or distributed for profit or commercial advantage and that copies bear this notice and the full citation on the first page. To copy otherwise, or republish, to post on servers or to redistribute to lists, requires prior specific permission and/or a fee.

ITiCSE'11, June 27-29, 2011, Darmstadt, Germany.

Copyright 2011 ACM 978-1-4503-0697-3/11/06...\$10.00.
$[6,9,12]$. One commonly used strategy is to call attention to successful women in computing, to act as role models for female students.

In this paper, we describe our recent contribution to these efforts a 60-page 'fun' booklet, published in May 2010, aimed at secondary school students (ages 14-18). The booklet tells the stories of contributions made by women in computing, and gives some examples of the research accomplishments made by contemporary women who have devoted their careers to computing. We look quantitatively and qualitatively at the initial responses from UK teachers to this initiative. In our future work, we will examine additional feedback from both students and teachers.

\section{BACKGROUND ON CS4FN}

Our booklet was part of a larger campaign, Computer Science For Fun (cs4fn) [3]. The cs4fn project is a widening participation scheme aimed at young people $(10+)$, which gives them a taste of current research and deep principles in computing, presented in a style that is engaging and straightforward. It began in 2005 at Queen Mary, University of London. A 2006 review by the UK's Engineering and Physical Sciences Research Council (EPSRC) named cs4fn an example of good practice. In 2008 the EPSRC awarded cs $4 \mathrm{fn}$ major funding enabling the project to expand on an assured financial footing, and in the same year Google added its financial support as part of its CS4HS programme for Europe, the Middle East and Africa. In 2011, cs4fn has a global audience and university partners across the UK, Europe and North America.

The cornerstone of the cs4fn campaign is a twice-yearly 20-page magazine, aimed primarily at secondary school students. It is distributed, free of charge, to ICT teachers at UK secondary schools, and is available for anyone in the world to subscribe, also for free, via a form on our website. The stories in the magazine are usually taken from specific research projects, but sometimes the subject is a core topic of computing (e.g. binary numbers, NPcompleteness) or a story drawn from the history of computing. In each case, we find an engaging real-life basis for the story and explain the computing in those terms. We show that computing can be a vehicle for accomplishing amazing things and solving interesting problems in whatever field excites the reader (e.g. robotics, mathematics, art, language, biology, sport). We have documented the success of this general approach elsewhere $[3,4,5]$. 
As part of our EPSRC funding, we produce annual compendiums of stories from the cs $4 \mathrm{fn}$ magazine. The first such edition simply collected the first three issues of cs $4 \mathrm{fn}$, but for the second edition we believed that it would be worthwhile to collect stories from the entire history of cs $4 \mathrm{fn}$ in which research by women was featured, as well as writing new content by and about women in computing. It is the early evaluation of this initiative on which we report here.

\section{CONTEXT AND RELATED WORK}

\subsection{Female engagement with computing}

For more than two decades, computer science has been battling the decline of female student interest and self-confidence in computing, especially as girls get older [18]. Unfortunately for computer science enrolment figures, this decline coincides with the age when students begin to make career decisions. As a consequence, female enrolment in CS degree courses is declining in many countries [13], with no change to the trend in sight [1].

The pervasive stereotype is that computing as a domain is somehow essentially male. This has measurable effects on young women's confidence in computing: Moorman and Johnson showed that female students rated their abilities less highly than their male counterparts, despite achieving higher average marks [14]. Meanwhile, Fisher and Margolis cite a drop in confidence as a precursor to declining interest [8]. Therefore, employing strategies to maintain and enhance female students' initial confidence may be a useful way of retaining their interest.

\subsection{How role models can help}

One common approach to raising female confidence in computer science is by increasing the visibility of female role models in the field [10]. Calling attention to successful females in computing shows young women that the unwelcoming stereotype is wrong and can be subverted. In addition, it shows girls that women are present and making significant contributions to the field. This, in turn, may inspire girls themselves. Many initiatives that aim to inspire girls do so by having students meet real computer scientists, like Microsoft's Digigirlz [6], Carnegie Mellon's Women@SCS Roadshows [9] and The Digital Divas programme in Victoria, Australia [12]. Other programmes do not rely on the role models actually being present - using video for example $[16,17]$ - this experience, though more remote, is more easily scaled and disseminated. Still additional research shows that changing objects in a computer science classroom or laboratory from being stereotypically computer science-like (i.e., interpreted as male; such as Star Trek posters and video games) to more neutral items (e.g., nature posters) raised female students' interest in computer science to levels comparable to that of male students [2]. A project that places its emphasis on women's contributions to computing, and could be distributed relatively easily and cheaply, should be a useful contribution to help inspire female students who might be feeling the effects of the negative stereotypes of women in computing.

\subsection{A cs4fn approach to inspiring students}

We postulated that a booklet in the cs4fn style about women in computing would fit the above criteria. We write the cs $4 \mathrm{fn}$ magazine in such a way that researchers and their findings are given prominence and made relevant to students' everyday life contexts, thereby providing the potential for the reader to cast the researchers as role models. Comments from teachers tell us that they appreciate the regular cs4fn magazine as an effective tool for consistently inspiring their students. For example, one American teacher requested copies of a different issue of cs4fn magazine for her class, framing her request in terms of inspiration: "My goal is to give them skills and inspire them to think deeper, to explore and create."

\section{THE BOOKLET}

\subsection{Look and feel}

The finished booklet itself comprises sixty glossy, full-colour A4 pages with a paperback-style binding. The design and layout are magazine-style with bold colours and lots of images, designed by the publications department at our university. We publish all our materials this way; readers get a rich, good-quality physical impression from the aesthetic experience of the booklet as well as from the text. In short, we aim to ensure the materials will be as attractive and fun to read as a mainstream publication for young adults.

\subsection{Content}

\subsubsection{Stories about current female researchers}

The great majority of the 44 articles in the book are about original research done by women. Some of these examples are current research, for example Anje-Margriet Neutel's work on biosphere complexity for the British Antarctic Survey, and others are on work that has become a cornerstone of CS, such as Fran Allen's development of compilers. In all of the articles on research, the science and its context is in the foreground - reading the two articles mentioned will teach a student why understanding the complex rules that govern an ecosystem can help the organisms in it survive, and how an optimising compiler helps a program run faster than the unoptimized code. However, these stories also tell the story of the scientist doing the work. In the case of the article on Allen's work, the story mentions how she won the Turing Prize, showing how women have risen to the top of the computing profession. In the story on Neutel, we explain that her background is in linguistics rather than ecology, which introduces readers to the interdisciplinary nature of CS, and how it rewards rather than hinders diverse interests in its practitioners.

\subsubsection{Stories about history and gender}

Other articles are about historical women in computing, like Ada Lovelace and Florence Nightingale, showing that women were pioneers in computing and the visualisation of data. Other article topics deal with gender issues more explicitly: for example, about women as portrayed in films about technology, female entrepreneurs in technology, organisations for female computer scientists and what we call "a gendered timeline of technology": a timeline that runs through the booklet, providing mini-histories of technology with a focus on gender issues.

\subsubsection{Stories about students}

It was important for us to tell the stories of aspiring female computer scientists too; the steps on the ladder to international success and groundbreaking work must be made explicit. There are numerous stories about students in the booklet, such as a secondary school student who won a computer animation competition with a short film about the Iberian lynx. We also talk about student groups like Women@SCS at Carnegie Mellon University, who have set up a mentoring and support network for 
students and graduates, and the Nerd Girls, a group based at Tufts University who created alternative energy systems for an island off the east coast of the USA. These stories show readers that it is possible to create innovative work in CS at any age.

\subsubsection{Stories by women}

In this special issue of cs $4 \mathrm{fn}$ we also invited female researchers to write articles about their own work and experience. Whereas most of the articles in the booklet are unsigned and written in the third person (following the style for cs $4 \mathrm{fn}$ articles in general), these particular articles are written in the first person and attributed to their authors. In this way we (as three men and one woman producing the booklet) seek to make sure that the 'voices' in it are either female or gender-neutral.

In summary, we hoped that anyone reading the booklet would find inspiration and encouragement inside. It was also essential that teachers immediately see the potential for inspiring students, as they choose how to use and distribute the booklet within their schools.

\section{PRINTING AND DISTRIBUTION}

In order to achieve the widest possible readership for the booklet, we printed 15,000 copies and sent them by post to both our regular UK teacher subscribers and unsolicited to ICT teachers and librarians in UK secondary schools. Our first round of distribution was an unsolicited mailing to UK secondary schools. Each school on our list received two separate copies, one addressed to the subject leader for ICT (as computing classes are known in the UK) and another to the library/LRC manager. In our second round of distribution, we sent copies to the teachers in the UK who have subscribed to the cs4fn magazine via our website, for themselves and/or to distribute to their classes. We allocated roughly $20 \%$ of our total printing to send to teachers who requested more, and for our own use as giveaways when visiting schools and festivals during our normal outreach activities.

We also distribute the booklet online. A PDF version of the booklet is available for free on our website at http://www.cs4fn.org/annual/cs4fnannual2.pdf. In this paper we focus exclusively on the response to the printed booklet, but the PDF version has proven popular: from April 2010 to January 2011 it had been downloaded 9420 times.

\section{THE RESPONSE}

\subsection{Requests for more copies}

The first responses to the unsolicited mailing came about four days after the mailing began. Almost all the responses to the mailing came within five working days of each other, and within nine working days of the mailing.

In total we received 74 requests for extra copies from teachers, amounting to 1838 copies. The mean number of copies requested was around 24 copies, and the mode of the requests was $30-$ larger than the average secondary class in England and Wales [10]. Comparing data from the previous three mailings of the standard cs4fn magazine, sent to a comparable number of teachers, the women's edition garnered roughly three times the response.

Of the 74 requests, 72 were sent to teachers in the UK, four copies were sent to Scotland, two to Wales and one copy to Northern Ireland. Five requests for the magazine were sent to the teachers' individual homes. We can break down details of the 69 schools remaining. Of these schools, 50 were secondary/6th form schools (meaning students attend them from the ages of 11-18). Eight were 6th form only (education from 16-18), seven were secondary only (from 11-16), one school was primary/secondary (from 5-16) and three offered education for all age groups from 5-18. There were 62 state schools and seven were independent. Mixed gender schools accounted for 59 schools, while eight were girls' schools, one was a girls' school with a mixed 6th form, and one was a boys' school with a mixed 6 th form.

\subsection{Teacher comments}

We also provided a space on the web subscription form for teachers to write comments about why they were ordering extra copies. Of the 74 requests for additional copies of the magazine, 66 teachers left comments. In future work we will conduct a more detailed analysis of the responses from teachers. Here we present a preliminary analysis of themes that emerged from the requests we received.

\subsubsection{Comments about the booklet}

The comments were overwhelmingly positive about the booklet itself. Teachers reported not only that they found the booklet interesting and informative, but also appreciated the fact that the stories spanned different subjects within computing and across the arts \& sciences. A few specifically appreciated a computing book that emphasised fun. One thought that having the magazine in her library might make the library 'cool'.

Some teachers made comments that suggested our belief about the importance of the physical look and feel are substantiated. For example, a teacher wrote: "I showed it to some of my pupils who enjoyed its content and loved the layout of the topics." Another praised the format: "For some reason, glossy mags attract our students much more that a PDF - sorry about the trees."

\subsubsection{Comments about inspiring girls in computing}

Teachers' comments focused on two distinct but associated themes relating to inspiring their female students. For some, the main attraction of the magazine is simply the 'wow factor', which they hope excites girls in a positive way. One teacher mentioned the effect on their students: "Girls were enthralled by the copy [of the booklet] that you kindly sent us." Another wanted "as many multiple copies as it is possible to receive to inspire our students."

Other teachers linked the idea of inspiring students to gender imbalance. Teachers reported difficulty in inspiring girls to take ICT/computing classes, and saw the magazine as a significant resource in motivating them. Some teachers had watched an almost equal balance between genders in younger years become more disparate in upper years. As one teacher states: "This is just the motivation we need to promote Computing Science to girls in school. In middle school the divide is even but in upper school the tendency is for boys to continue studying and the girls to drop out of this field". Some teachers said that their female students viewed computing as a subject more suited to males, and they thought that the magazine would help change that perception. For example one wrote: "Girls in our school view ICT as a 'boys' subject' therefore it would be great to have some positive material to promote the subjects for girls." 


\section{DISCUSSION}

Our focus in this paper has been on teacher responses to the booklet for a number of important reasons. Teachers will act as the gatekeepers for any outreach project that incorporates school students. Securing their enthusiasm is therefore essential to success. The interest we have received from teachers over an extended period, as well as their positive comments, demonstrates that they believe the cs4fn model for inspiring and encouraging students is right for the job. It is important that teachers have been so enthusiastic, and believe along with us that the booklet will engage young women with computer science.

\subsubsection{Which teachers responded?}

The requests for copies were divided between state (free-tostudent) schools and independent (fee-paying) schools in a way that reflected current schooling provision in the UK: the percentage of requests from independent schools (11.3\%) was close to the actual percentage of independent schools in England (9.1\% in 2007) [7]. This suggests that female engagement with computing is seen as an important issue throughout the UK educational sector, and that our magazine fits the requirements of both state and independent teachers. In terms of widening participation, this also means that our booklets are getting into the hands of traditionally harder-to-reach audiences in state-funded schools. Most of the teacher requests came from mixed-gender schools, which means boys will be exposed to the booklet as well - especially those in schools that have ordered copies for all their computing students. Sosik and Goldshalk assert that males may derive more benefit from cross-gender role models than females [15]; therefore there may be a bonus role model benefit to males as well, even though they are not the primary audience for the booklet.

\subsubsection{Teacher comments}

Teachers commented on the design and layout of the magazine, finding it eye-catching and exciting. In addition to comments about the aesthetics of the magazine, teachers were overwhelmingly positive about the content. They reported that the booklet would be flexible enough to benefit current female computing students, to motivate and retain them, and also to attract new female students to take a subject that they may have felt excluded from before.

Teacher responses also indicate that they share our desire for girls to be better represented in computing, as indicated by their positive response to a booklet that puts the issue right on the cover, supported by the tendency for comments to mention the difficulty in recruiting girls to computing. We seem to have tapped into a shared priority in computing education. The fact that the response to a booklet featuring this particular topic was so much larger than other cs4fn issues can be taken to indicate that teachers are specifically looking out for computing material for girls, perhaps more so than material about computing in general.

\subsubsection{Initial lessons from the cs4fn approach}

Though our formal evaluation will appear at the completion of the cs4fn project grant in 2013, there are informal lessons from the production and distribution of the booklet that we would like to note. First of all, as reported elsewhere, the fact that $\operatorname{cs} 4 \mathrm{fn}$ is free seems to be important to its success [5]. In the specific case of the 'women in computing' booklet we are working to achieve what might be seen as a 'soft' goal - increasing participation of a particular group, rather than a 'hard' curriculum-based goal like trying to teach a particular programming language. For that reason a free resource may be much easier to take up, as there is no need for a teacher to justify the expense, or take up valuable time going through a school's procedure for ordering and payment.

The success of the response from teachers may owe much to the booklet's cover design which made its topic and purpose clear. The design and layout of the booklet have been shown to help attract teachers, and teachers in turn believe that students will be attracted by it as well. This is evidenced not only by the number of requests for class sets to give to students, but also their comments that specifically refer to expected student response.

\section{CONCLUSIONS}

By almost any measure, the response to the cs $4 \mathrm{fn}$ 'women in computing' booklet was extremely positive. We received around three times as many teacher requests for the booklet as we had for a typical issue of cs4fn magazine (based on an average of the last three issues). We also received positive comments from almost every teacher who responded. They enthused about the booklet's content and appearance, and thought that it would help encourage more girls to take up (and stick with) computing, as we had hoped it would.

There is clearly further evaluation work to be done on student responses to the booklet, and the question of how it can impact on female uptake of computing. Student responses may be different to teachers' expectations. We have recently started to collect data from university students about the effect of the cs $4 \mathrm{fn}$ magazine on their enrollment in computer science courses with initial data suggesting that cs4fn has encouraged both male and female students to take the subject at university. What we can say about our results from teachers is that teachers share many of the same concerns we do. They too are interested in inspiring students, particularly young women, and felt that a booklet such as ours was extremely useful to help them achieve their aims. We will continue to monitor and analyse feedback - and are planning a deeper, grounded theory-based analysis of the teacher responses to extract more information from this corpus.

We created the booklet in order to inspire female students, and teacher response suggests our approach has struck a significant chord. Women have been under-represented in computer science and teachers are seeking resources to help combat this problem. Telling the stories of women in computing may help to enthrall, inspire and attract more to the field in the future.

\section{ACKNOWLEDGMENTS}

We are grateful to our funders including EPSRC (EP/F032641/1), the Westfield Trust, Google, ARM and Microsoft. We are also grateful to Karen Shoop of the School of Electronic Engineering and Computer Science at Queen Mary, University of London.

\section{REFERENCES}

[1] Becerra-Fernandez, I., Elam, J., and Clemmons, S. 2010. Reversing the landslide in computer-related degree programs. Commun. ACM 53, 2 (Feb. 2010), 127-133. DOI= http://doi.acm.org/10.1145/1646353.1646387

[2] Cheryan, S., Plaut, V. C., Davies, P.G., and Steele, C.M. Ambient belonging: How stereotypical cures impact gender 
participation in computer science. Journal of Personality and Social Psychology 97, 4 1045-1060.

[3] Curzon, P. 2007. Serious fun in computer science, ACM SIGCSE Bulletin 39(3) p1. Invited keynote at ITiCSE07. DOI= http://doi.acm.org/10.1145/1269900.1268785

[4] Curzon, P., Peckham, J., Taylor, H., Settle, A., and Roberts, E. 2009. Computational thinking (CT): on weaving it in. SIGCSE Bull. 41, 3 (Aug. 2009), 201-202. DOI= http://doi.acm.org/10.1145/1595496.1562941

[5] Curzon, P., Black, J., Meagher, L. R., and McOwan, P. W. 2009. cs4fn.org: Enthusing Students about Computer Science. In Proceedings of Informatics Education Europe IV, Hermann, C, Lauer, T., Ottmann, T. and Welte. M. Eds., (Freiburg, Germany, November 5 - 6, 2009), 73-80.

[6] Digigirlz Programs: Digigirlz Day, 2009. Retrieved 22 August 2010, from Microsoft: http://www.microsoft.com/about/diversity/programs/digigirlz /digigirlzday.aspx

[7] DCSF (Department for Children, Schools and Families) (2007a) Schools and pupils in England, January 2007 (final), London: DfES. Retrieved 22 August 2010, from the DfES: www.dfes.gov.uk/rsgateway/DB/SFR/s000744/index.shtml

[8] Fisher, A. and Margolis, J. 2002. Unlocking the clubhouse: the Carnegie Mellon experience. SIGCSE Bull. 34, 2 (Jun. 2002), 79-83. DOI= http://doi.acm.org/10.1145/543812.543836

[9] Frieze, C. 2005. Diversifying the images of computer science: undergraduate women take on the challenge!. SIGCSE Bull. 37, 1 (Feb. 2005), 397-400. DOI= http://doi.acm.org/10.1145/1047124.1047476

[10] Gürer, D., and Camp, T. 2002. Investigating the Incredible Shrinking Pipeline for Women in Computer Science. Final Report, NSF Project 9812016.

[11] Hansard HC vol 498 cols 220W (25 Nov 2009).

[12] Lang, C., Craig, A., Fisher, J., and Forgasz, H. 2010. Creating digital divas: scaffolding perception change through secondary school and university alliances. In Proceedings of the Fifteenth Annual Conference on innovation and Technology in Computer Science Education (Bilkent, Ankara, Turkey, June 26 - 30, 2010). ITiCSE '10. ACM, New York, NY, 38-42. DOI= http://doi.acm.org/10.1145/1822090.1822103

[13] Millar, J., and Jagger, N. 2001. Women in ITEC courses and careers. London, Department of Education and Skills, Department for Employment. The Women's Unit: 156.

[14] Moorman, P. and Johnson, E. 2003. Still a stranger here: attitudes among secondary school students towards computer science. In Proceedings of the 8th Annual Conference on innovation and Technology in Computer Science Education (Thessaloniki, Greece, June 30 - July 02, 2003). D. Finkel, Ed. ITiCSE '03. ACM, New York, NY, 193-197. DOI= http://doi.acm.org/10.1145/961511.961564

[15] Sosik, J. J., Godshalk, V. 2000. The Role of Gender in Mentoring: Implications for Diversified and Homogenous Mentoring Relationships. Journal of Vocational Behavior. 57, 1 (August 2000) 102-122, DOI= http://dx.doi.org/10.1006/jvbe.1999.1734.

[16] Teague, J. 2002. Women in computing: what brings them to it, what keeps them in it?. SIGCSE Bull. 34, 2 (Jun. 2002), 147-158. DOI= http://doi.acm.org/10.1145/543812.543849

[17] Townsend, G. C. 1996. Viewing video-taped role models improves female attitudes toward computer science. In Proceedings of the Twenty-Seventh SIGCSE Technical Symposium on Computer Science Education (Philadelphia, Pennsylvania, United States, February 15 - 17, 1996). K. J. Klee, Ed. SIGCSE '96. ACM, New York, NY, 42-46. DOI= http://doi.acm.org/10.1145/236452.236491

[18] Volman, M., and van Eck, E. 2001. Gender Equity and Information Technology in Education: The Second Decade. Review of Educational Research 71, 4 (Dec 2001) 613-634. DOI $=10.3102 / 00346543071004613$ 